\title{
The Relationship Between Rational Cooperation and Constrained Maximizers
}

\author{
Deng Siyang \\ School of Public Administration, Nanjing Normal University, Nanjing, China
}

Email address:

605887459@qq.com

\section{To cite this article:}

Deng Siyang. The Relationship Between Rational Cooperation and Constrained Maximizers. International Journal of Philosophy. Vol. 8, No. 4, 2020, pp. 98-103. doi: 10.11648/j.ijp.20200804.13

Received: December 6, 2020; Accepted: December 21, 2020; Published: December 28, 2020

\begin{abstract}
From the perspective of actors' pursuit of rational self-interest, Gauthier's contractarianism links justice, rationality and morality, he attempts to deduce moral principles from non-moral premises by combining the method of contract theory, rational choice theory and game theory, and establish a just contract between rational actors to provide a plan of action for "How can I pursue a better life?". He tried to argue why rational actors chose to cooperate rather than from a normative point of view. He tried to prove that the actor's choice of cooperation is the result of rational choice because cooperation will improve the actor's situation. He believes that rational actors will choose to cooperate with people in a just and rational way, and rational actors will voluntarily abide by the contract and limit their behaviors in order to pursue a better social life. But his argument for cooperation lacks stability fails to fully prove why we should choose this mode of cooperation instead of that mode of cooperation and his argument for the rationality of cooperation is not convincing enough. He fails to demonstrate that collaboration is better than non-collaboration at all times, nor does he fully demonstrate that it is irrational to collaborate with actors other than constrained maximizers. Although his argument has some flaws and cannot convince all opponents, it provides us with a new answer to this question.
\end{abstract}

Keywords: Gauthier, Contractarianism, Cooperation, Constrained Maximizer, Rational

\section{Introduction}

Since the 1950s, modern rational choice theory has gained further development. Rational choice theorists have developed theories of motivation, behavioral restriction, calculation and reasoning for behavioral choice, which have gradually gone beyond the scope of political science and been widely applied in the fields of political science and economics, providing new possibilities for theoretical construction and scientific theory within the scope of various disciplines. With the publication of A Theory of Justice, political philosophy began to get people's attention again. Moral philosophers political theorists and economists paid great attention to the view of justice in contract theory. David Gauthier is a neo-Hobbesian social contract theorist, his goal is to create a rational choice theory that incorporates moral theory.

In his theory, Gauthier tries to leave out those more complicated factors and simplifies the selection process. In Gauthier's view, "The theory of rational choice is an ongoing enterprise, extending a basic understanding of value and rationality to the formulation of principles of rational behavior in an ever wider range of situations." [1] By analyzing and comparing the various possible outcomes, Gauthier believes that rational actors will choose the action plan that is likely to produce a greater expected utility, and in most cases, this result is related to the cooperation between rational actors. After the publication of Gauthier's Morals by Agreement in 1986, it attracted a lot of attention from all circles of society, including philosophers, ethicists, economists and jurists, etc., and a large number of critical articles appeared on Morals by Agreement. There are many different kinds of cooperation, what kind of cooperation is rational in Gauthier's view? What kind of people does the actor cooperate with to achieve the expected utility? In response to these questions, much of the discussion of Gauthier's contractarianism took place in the 1980s. Gauthier has developed his own answers to these questions. His theory provides a good way for people to understand contract theory, moral theory and rational choice theory from the perspective of self-interset, but with the practical application, people will find it is difficult to be 
widely used. With the development of the times, people continue to develop and improve his theory. Although there are fewer relevant documents in the new period than in the last century, it still has certain theoretical value.

\section{The Rationality of an Agent Being a Constrained Maximizer}

Gauthier points out, "what I have self-anchored reason to do must depend entirely on the causal efficacy of my possible actions - on what they would or might bring about." [2] The actors choose and act based on their own considerations. Although Gauthier does not believe that the public interest of the whole society can be realized only by pursuing the maximization of their own interests, he does not deny that the whole society has the possibility of development in the process of the actors pursuing their own interests. From the perspective of self-interest, Gauthier distinguishes between those who are inclined to maximize their own satisfaction or interests in any particular choice they make, and those who are inclined to obey the mutually beneficial moral constraint on the premise that they expect others to also obey it. He said:"a straightforward maximizer is a person who seeks to maximize his utility given the strategies of those with whom he interacts. A constrained maximizer, on the other hand, is a person who seeks in some situations to maximize her utility, given not the strategies but the utilities of those with whom she interacts." [3] The interests that Gauthier's contractarianism is concerned with are those derived from agreements, and those interests are determined by the influence that each individual can have on the interests of his peers.

There are differences in the way constrained maximizers interact with those with similar dispositions and in the way they interact with straightforward maximizers. Only those who tend to abide by the agreement are reasonable and acceptable as parties to the agreement. Those who tend to cooperate only cooperate with those who they perceive as similarly inclined, and a straightforward maximizer has no opportunity to benefit from appearing as a constrained maximizer. Straightforward maximizers tend to take advantage of their peers when they have an opportunity; once this is known, the constrained maximizer prevents the opportunity from being created. In the same opportunity, the straightforward maximizers are bound to get greater benefits. Since they have different tendencies, the straightforward maximizers and the constrained maximizers also have different cooperation opportunities, thus benefiting the latter. A constrained maximizer conditionally tends to cooperate in a way that everyone follows, producing near-optimal and fair results, and will cooperate in this way when he might actually want to benefit from it. For Gauthier, the more constrained maximizers there are in a society, the closer it is to the ideal social state.

Abstract from the prisoner's dilemma case, Gauthier recognize the seriousness of the problem - "in any situation with a structure parallel to that faced by Fred and Ed, supposedly rational utility-maximizers do much worse for themselves than could supposedly irrational optimizers." [4] This indicates that the pursuit of utility maximization is not a rational choice under some circumstances, because from the perspective of individual utility maximization, one's own situation is not in an optimal state. Since there are other, better alternatives, the alternative must not be optimal, and therefore not rational. Given consistent expectations, a mutual best reply is an equilibrium outcome. The requirements of rational choice theory stipulate that, in an ideal world, the best reply for each actor can only be a necessary and not sufficient condition of the theory. The equilibrium outcome is not necessarily the optimal one, both the mutual compliance agreement and the breach of the agreement are the equilibrium outcomes, but there is only one optimal reply, namely the mutual compliance agreement, only in this way can the equilibrium outcome of the optimal reply be produced.

Joseph Mendola posed the distinction between rationality as intelligibility and rationality asintelligibility, claming that "Individual utility maximization is primarily a theory of rationality as intelligibility......It may seem as if those who possess rationality as justification would be able to escape such dilemmas...... we should not formulate a conception of rationality as justification as if it were an alternative to a conception of rationality as intelligibility." [5] He thought Gauthier appears to confuse the distinction between the two, thus creating inconsistency in constrained maximization. Gauthier is not opposed to individual utility maximization on all occasions, but his rationality considers both intelligibility and intelligibility.

To avoid possible misunderstanding, Gauthier notes that neither conception of rationality requires that practical reasons be self-interested. "On the maximizing conception it is not interests in the self, that take oneself as object, but interests of the self, held by oneself as subject, that provide the basis for rational choice and action. On the universalistic conception it is not interests in anyone, that take any person as object, but interests of anyone, held by some person as subject, that provide the basis for rational choice and action." [6] If I can profit from your welfare, then, in the concept of universality, I have reason to promote the growth of your welfare. But having a reason to do something does not necessarily mean that the agent will do it.

If agents are in a society where most people are straightforward maximizers, or rather a state of nature, then the constrained maximization that leads them to favor justice is actually of no use to them, and they must consider only the immediate requirements of their utility. Gauthier argues that "in a world of Fooles, it would not pay to be a constrained maximizer, and to comply with one's agreements. In such circumstances it would not be rational to be moral." [7] But if actors find themselves with rational and just people, then they also have reason to lean toward justice. In a community where most people tend to adhere to fair and optimal agreements and put them into practice, actors willing to base their actions on joint cooperative strategies will be a self-sustaining society. Such a world would provide rational cooperative actors with 
benefits that Fooles who would not cooperate would not enjoy. Gauthier does not claim that rational actors are constrained maximizers under any circumstances, but make behavioral choices according to the actual situation. " The best theory for oneperson decision problems underwrites expected utility maximization." [8] Therefore, it is rational choice to constrain one's behavior in the case that it is better for one to be a constrained maximizer.

\section{Gauthier's Argument for the Rationality of Cooperation}

Gauthier argued that practical considerations should be distinguished from practical reasons. The reasons why a person does something are facts, and these facts should be considered in doing it, whether or not they really exist. In Gauthier's view, the word reason implies the existence of a critical position that naturally leads to belief and behavior. One reason is a well-informed, well-thought-out and validated practical consideration. "A perfectly rational agent would be moved by those facts she acknowledges as reasons, and that an agent not moved by some fact he acknowledges as a reason reveals thereby either that his acknowledgement is mistaken or that his motivation is imperfectly rational." [9] Why does Gauthier advocate cooperation and contract between actors? What's his reason for doing this?

In Gauthier's view, justice and reason are an ideal state of cooperative interaction between rational actors. "Co-operation may then seem a second-best form of interaction, not because it runs counter to our desires, but because each person would prefer a natural harmony in which she could fulfil herself without constraint. But a natural harmony could exist only if our preferences and capabilities dovetailed in ways that would preclude their free development. Market and morals tame this conflict, reconciling individuality with mutual benefit." [10] When the interaction of the market presets the harmony between equilibrium and optimality beyond good and evil, and in the presence of free riders and parasites, the natural interaction degenerates into force and fraud, the cooperative interaction is the field of justice. Where practical rationality is satisfied, cooperation ensures the elimination of free-riding and parasites peculiar to our natural conditions, so that we can determine justice in terms of rational tendencies toward cooperative behavior.

How can an actor make a rational choice based on available information, and that rational choice happens to be cooperation? Considering the choice of an actor who makes a decision based on the expectation of the choice of others, each person decides the course of action based on the expectation of the choice of others, and realizes that the other person knows this and makes the choice based on this. Since situations involving individual actors may be seen as limiting interactions, the approach of game theory can be used to adequately generalize about rational behavior. For example, in the prisoner's dilemma, an actor makes a behavioral choice based on the consideration of personal utility maximization, and because the other actor makes the same thinking, both of them make a choice from the perspective of self-interest maximization, which in turn leads to the fact that their actual outcome is far from the expected outcome. This is because when making behavioral choices, the actor does not take into account that other people's choices will also lead to changes in his own situation. He just chooses the outcome that seems likely to give him the best situation and acts according to the plan that produces that result. As long as others who can influence the actor's situation do not act in accordance with the scheme envisaged by him, the actor is unable to achieve the outcome foreseen and may, instead, worsen his situation by the actor's choice. In the game, in addition to considering his own behavior choice, one should also consider the influence of others' choice on his own choice result, and choose the most favorable result according to the available information.

In order to avoid the prisoner's dilemma, actors will realize that cooperation is effective and that there are good reasons for cooperative interaction. So if, as Gauthier endorses, "valid moral requirements are practical reasons, and if practical reasons are related, whether directly, or indirectly in ways yet to be considered, to one's concern with one's own fulfillment, then a normally rational person, aware of the relation between moral requirements and her own fulfillment, can be expected to be motivated, at least to some extent, to comply with those requirements." [2] Through fair and reasonable cooperation, rational actors will obtain more satisfaction than those who only value their own satisfaction, and cooperation is not only a choice of behavior, after the intention of cooperation is reached, cooperation must be observed. Only in this way can the original actors reach the purpose of formulating cooperation agreements, and the process of abiding by the contract is also a moral behavior.

By virtue of Proviso, the principle of minimax relative concession, constrained maximizer and other concepts, Gauthier tries to ensure that every actor participating in cooperation has the best possible situation, and only in this way can more and more actors be attracted to participate in cooperation. As more people participate in the cooperation, there will be more people in the whole society who will play by the rules of contract. According to Gauthier's theory, the higher the proportion of rational actors in a society's population, the more orderly the whole society will operate, and the situation of the actors involved in cooperation will be better than before. Therefore, cooperation is not only the result of game, but also a rational choice.

The problem of compliance is "A thorny problem for contract theories that seek to derive morality from rationality." [11] Rational actors can make a comparison between the expected utility of cooperation and the expected utility of non-cooperation, and they will find that in the long run, rational actors each give up part of their interests to regulate the behavior of themselves and others. They will benefit more from cooperating with each other than in a state of war with others in a non-cooperative state, so they are willing to be rational collaborators. Even if, in the short term, their self-interest may be limited by consensual agreements that 
limit their pursuit of self-interest, their self-interest may be less than the unfettered realization of it, but this is only temporary, and no one can guarantee that his interest will not be violated later. Although the interests in the state of agreement are not necessarily the maximization of personal interests, it is second best and will not make their own interests in the worst case.

"Where the invisible hand fails to direct each person, mindful only of her own gain, to promote the benefit of all, cooperation provides a visible hand. " [12] Compared with the state of nature, cooperation does lead to a better social situation. On the other hand, Gauthier fails to articulate why cooperation over other forms of interaction is second best? Why does he choose this mode of cooperation over other modes of cooperation? How can he prove that this mode of cooperation is the best? His answers on these questions are not very convincing.

\section{The Object of Rational Cooperation}

From Gauthier's point of view, rationality increases the cost of natural human interaction, not only providing a remedy for the ills it causes, but also offering the prospect of new mutual benefits through cooperation."If mutual forbearance results in a state in which everyone is better off than in a state of universal injustice, then these opportunities for cooperation are valuable. Therefore, maximizers who are constrained by justice enjoy greater opportunities to benefit from this cooperation." [13] To cooperate, the behavior of the agent must be restrained so that the cooperation can proceed in an orderly and stable way.

In the case of multiple choices, if everyone knows, and everyone knows that everyone else knows the sufficient strategic structure of the interaction, then everyone knows everyone else's plan, so there is no reason for him to reject his own plan. If an actor betrays the cooperative plan, then the other actors will know what he really thinks and then change their own plans. After the change of others' plan, the original plan of the one who tries to gain more benefits by betraying the cooperation fails. In a hypothetical well-informed social cooperative enterprise, rational collaborators will not give up cooperation because they are well aware that only cooperation will bring them more benefits.

Gauthier thinks that rational agents are submissive in a narrow sense, not in a broad sense, he distinguished broad and narrow compliance. "A person disposed to broad compliance compares the benefit she would expect from co-operation on whatever terms are offered with what she would expect from non-co-operation, and complies if the former is greater." [14] A broadly compliant person is only willing to cooperate with those they think are like them, to the exclusion of others. "A person disposed to narrow compliance compares the benefit he would expect from cooperation with what he would expect from a fair and optimal outcome, and complies with a joint strategy only if the former approaches the latter." [15] In Gauthier's theory, a person disposed to narrow compliance only cooperates among internal members, which can guarantee his own interests to some extent, he ignores the freedom and right of others to pursue their own interests, and the right of the broadly or narrowly compliant person to choose not to cooperate. On the other hand, broad compliant people can gain additional benefits through a wider range of cooperation opportunities. If they are asked to give up this part of their rights simply for reasons of rational self-interest, they may be reluctant to reach an agreement and participate in the cooperation in the first place.

Gauthier fails to take into account the fact that in some cases the narrow sense of obedience has no one with whom to cooperate, and that his situation may deteriorate without affecting the interests of others, and that the opportunities for cooperation increase when the narrow sense of obedience becomes the broad sense of obedience. In general, a broad submissive can improve his or her situation by cooperating with others, but he or she receives a smaller share of the cooperative surplus than a narrow submissive. According to the general view of contract theory, both parties cooperate based on a consensus agreement. Then, the broad subject will consider the issue of distribution when deciding to cooperate. He is willing to participate in the cooperation, so the choice of the broad subject cannot be considered unreasonable. In some extreme cases, if special obedience into generalized not obey, he may be unable to survive, and people on the basis of cooperation is for the sake of the self-preservation the pursuit of the maximization of individual interests, survival is the first point, in this case, the general obedience is necessary, is also a rational choice.

Young-Ran Roh thought that "The disposition of constrained maximization presents the possibility of rational morality in that it is rationally chosen and also impartially applied." [16] But it should be noted that Gauthier limited who could cooperate, and not all people could equally enter into cooperation, that is, "only beings whose physical and mental capacities are either roughly equal or mutually complementary can expect to find cooperation beneficial to all. Humans benefit from their interaction with horses, but they do not co-operate with horses and may not benefit them. Among unequals, one party may benefit most by coercing the other, and on our theory would have no reason to refrain. We may condemn all coercive relationships, but only within the context of mutual benefit can our condemnation appeal to a rationally grounded morality." [17] Gauthier's theory is based on the voluntary agreement of actors for mutually beneficial cooperation, which excludes children, the elderly and the disabled and a series of actors at a disadvantage in social interaction, depriving them of the right to improve their lives by participating in cooperation to increase their own interests, which is unfair. If those who are born with certain defects are excluded from cooperation because of an immutable fait accompli, regardless of their desire to participate in the cooperation, it is not without taking away the rights of those who are not in the state of social cooperation. According to the general social contract theory, the people in the contract state have no right to interfere in the behavior of the non-contract state, and the contract of the Gauthier is not applicable to all 
people, and like his contract theory, its practical feasibility is challenged.

\section{Conclusions}

Gauthier used the theory of rational choice and game theory to demonstrate his own views, clarify the rationality and necessity of cooperation, and provide more convincing theoretical support for the development of contract theory. Frank Forman thinks highly of Gauthier's Contractarianism and thinks that "Morals by Agreement is a first attempt by a philosopher to bridge the gap between economics and ethics." [18] Gauthier has developed a new form of contract argument, which provided a theoretical source for later generations to use this argumentation. We should also be aware when we actually use this method, the game theoretic analysis of the bargaining problem also gave rise to the worry that no determinate and satisfactory answer can be given to the question of what rational, self-interested individuals would agree on in a pre-moral context. [19] Jeremy Neill pointed that "since real-world persons are motivated by different and more complicated concerns than the concerns that Gauthier highlights, and since their circumstances are different and more complicated than Gauthier's idealized initial situation, they ought probably to seek their cooperative guidance in reasoning forms that are closer to their existing strategies." [20] It is impossible to find and apply a theory that is completely consistent with a constantly changing world, and Gauthier's theory of contract provides a way of thinking that is well adapted to changing situations. When we make choices in real life, we could use the rational choice theory method, not only considering our own choice and its possible consequences, but also the interests of others and what consequences their choices will bring us, so that we could make choices as expected as possible.

Georgia Testa claimed that instrumental reason has problems in adequately accounting for individual good. [21] In some cases, it is true that we can improve our situation through rational cooperation, but how can we judge the behavior to be moral? People can do it from unethical premises, and difficult to identify. Gauthier just illustrates the necessity of cooperation from the point of view of internal rationality, without resorting to coercion, and without explaining how to ensure the smooth operation of cooperation, he just hopes that people will abide by their moral consciousness. Just as Robert Sugden said, "in the absence of some external mechanism for enforcing agreements, agreement would be pointless and cooperation would be impossible to achieve." [22] His theory is probably more of an economic man's rational choice theory than a moral theory, and I personally think his attempt to derive the moral behavioral goal from the non-moral premise fails. Although I don't think Gauthier's theory can lead to moral behavior, we can't deny that Gauthier values morality, and moral behavior is in most cases better than immoral behavior.

There are still some limitations to Gauthier's contractarianism. Are rational actors constrained maximizers?
Under what circumstances are rational agents not constrained maximizers? There are certain conditions and scope to cooperation between constrained maximizers, and under what circumstances is the cooperation between constrained maximizers rational? And so on a series of questions, to be further thought and answered. Although the above problems still exist in his theory, none of the theories is perfect and includes all the situations. We can choose the one that is most consistent with the actual situation in the concrete practice. Gauthier's theory does not fix people's behavior choice mode, but only provides people with a choice way of thinking, so it can be continuously developed and improved according to the changes of the times.

\section{Acknowledgements}

I would like to thank the postgraduate Research and Innovation Program of Jiangsu Province for supporting me. My project name is The Research on The Contractarianism of Gauthier, and the project number is KYCX20-1201, which enables me to complete this article better.

\section{References}

[1] David Gauthier Morals by Agreement New York: Oxford University Press, 1986, p. 4.

[2] David Gauthier, "Reason to Be Moral?" Synthese Vol. 72 No. 1 Kurt Baier Festschrift Part I (Jul. 1987) pp. 5-27.

[3] David Gauthier, Morals by Agreement, New York: Oxford University Press, 1986, p. 167.

[4] David Gauthier, Morals by Agreement, New York: Oxford University Press, 1986, p. 80.

[5] Joseph Mendola,"Gauthier's Morals by Agreement and Two Kinds of Rationality", Ethics, Vol. 97, No. 4, 1987. pp. 765-774.

[6] David Gauthier, Morals by Agreement, New York: Oxford University Press, 1986, p. 7.

[7] David Gauthier, Morals by Agreement, New York: Oxford University Press, 1986, pp. 181-182.

[8] David Gauthier, "Twenty-Five On”, Ethics Vol. 123 No. 4 Symposium: David Gauthier's Morals by Agreement (July 2013) pp. 601-624.

[9] David Gauthier, Morals by Agreement, New York: Oxford University Press, 1986, p. 8.

[10] David Gauthier, Morals by Agreement, New York: Oxford University Press, 1986, p. 19.

[11] Peter Timmerman, Moral Contract Theory and Social Cognition, Switzerland: Springer International Publishing, 2014, p. 10.

[12] David Gauthier, Morals by Agreement, New York: Oxford University Press, 1986, p. 113.

[13] Robert C. Koons, "Gauthier and the Rationality of Justice", Philosophical Studies, Vol. 76, No. 1, 1994, pp. 1-26. 
[14] David Gauthier, Morals by Agreement, New York: Oxford University Press, 1986, pp. 225-226.

[15] David Gauthier, Morals by Agreement, New York: Oxford University Press, 1986, p. 226.

[16] Young-Ran Roh, "Is the Disposition of Constrained Maximization Chosen Rationally?", Theory and Decision, Vol. 59, 2005, pp. 19-41.

[17] David Gauthier, Morals by Agreement, New York: Oxford University Press, 1986, p. 17.

[18] Frank Forman, "Reviewed Work(s): Morals by Agreement by David Gauthier", Public Choice, Vol. 56, No. 1, 1988, pp. 89-96.
[19] Johanna Thoma,"Bargaining and the impartiality of the social contract", Philosophical Studies, Vol. 172, No. 12, 2015, pp. 3335-3355.

[20] Neill, J. "The Gauthier Contract: Applicable or Not?" Res Publica 23, 2017, pp. 1-22.

[21] Georgia Testa, "Gauthier and theCapacity for Morality", Res Publica 9, 2003, pp. 223-242.

[22] David Gauthier and Robert Sugden, Rationality, Justice and the Social Contract, Hemel Hempstead: Harvester Wheatsheaf, 1993, p. 3. 